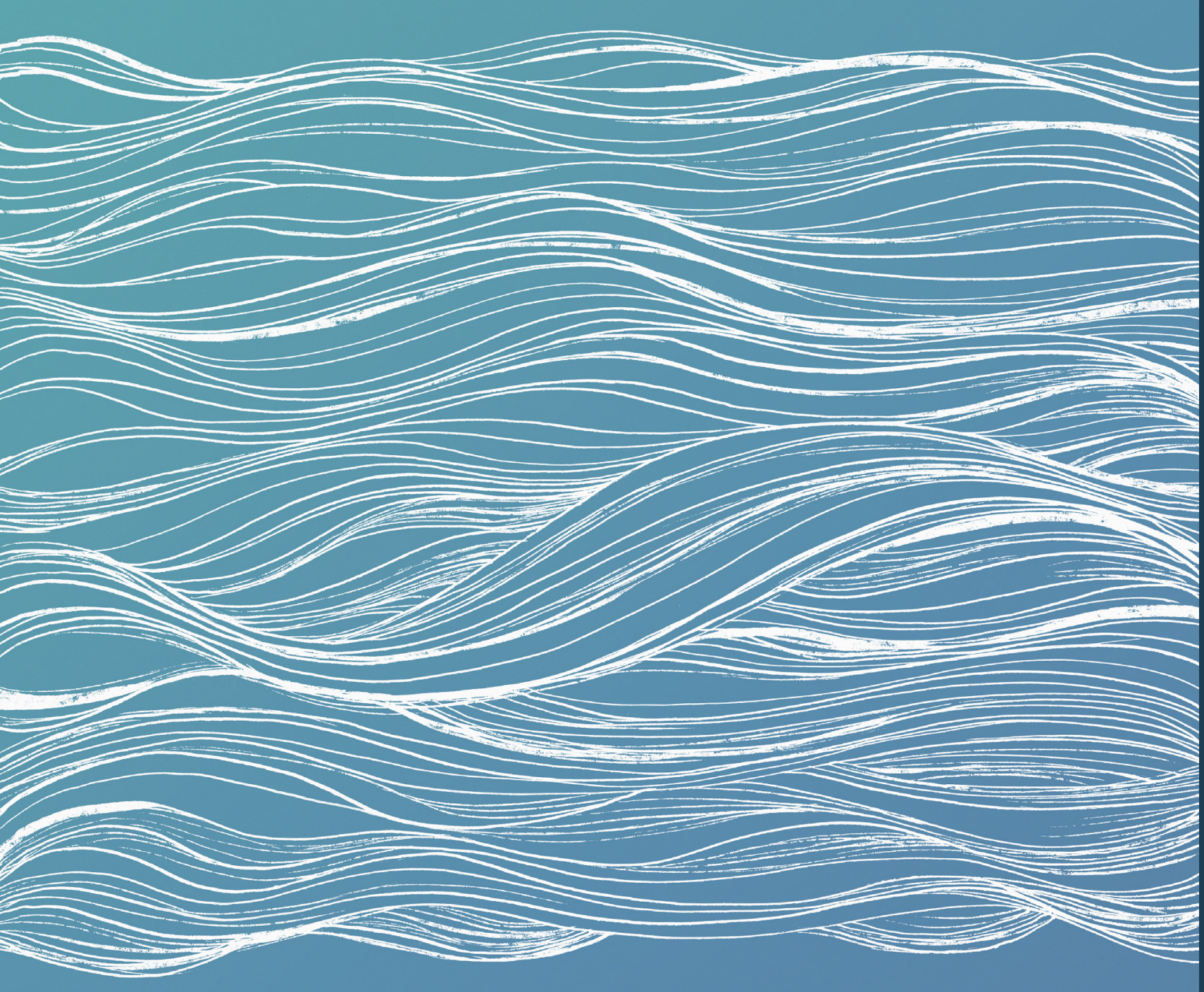

Genetics of inherited variability INCREASING UNIFORMITY BY REDUCING COMPETITION

ISSN: $1652-6880$

ISBN (print version): 978-91-7760-172-2

ISBN (electronic version): 978-91-7760-173-9

JOVANA MARJANOVIĆ

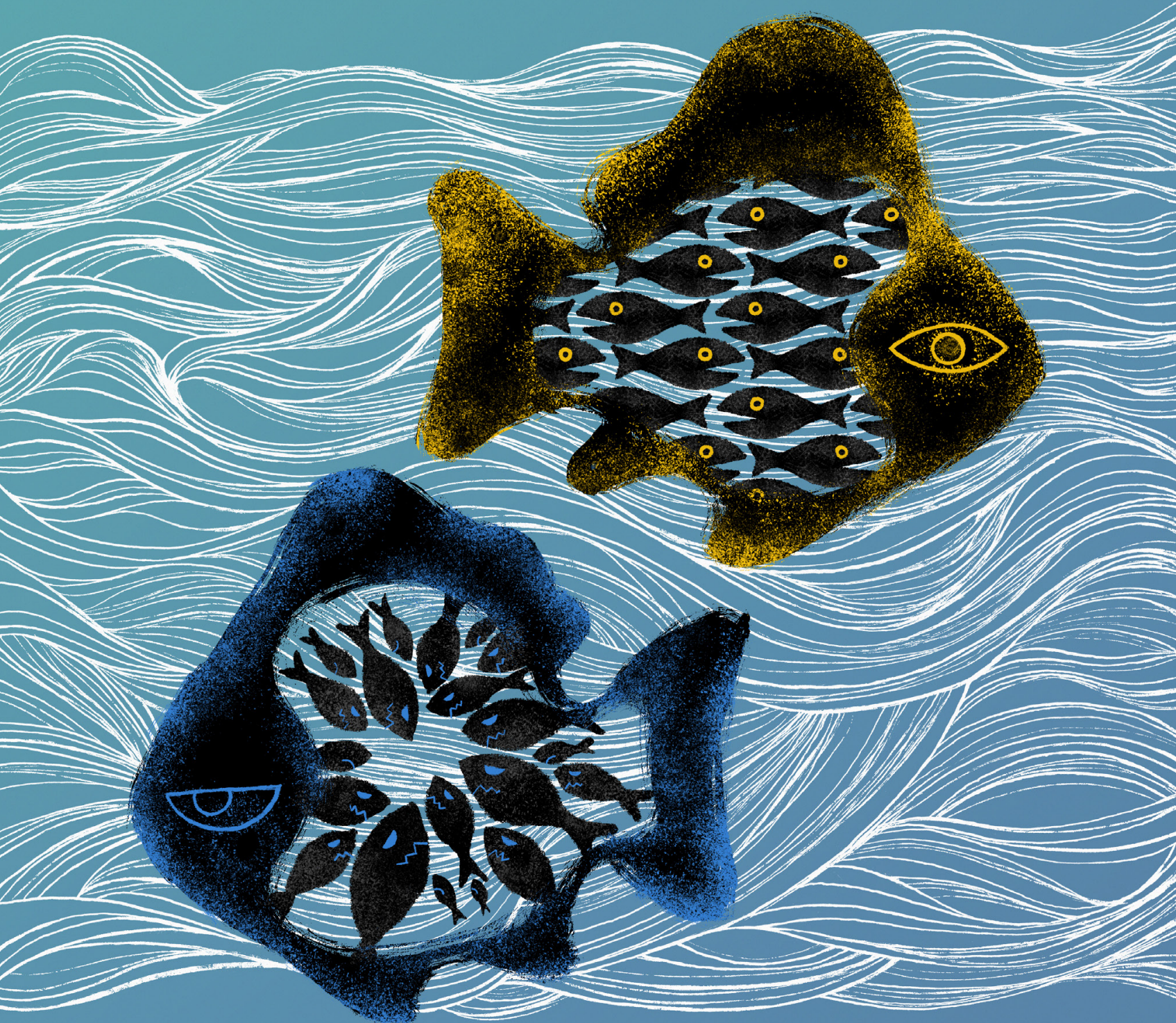

ACTA UNIVERSITATIS AGRICULTURAE SUECIAE DOCTORAL THESIS NO 2018:16
WAGENINGEN

$\underset{\text { SLu }}{d}$ 


\section{Genetics of inherited variability \\ Increasing uniformity by reducing competition}

Jovana Marjanović 


\section{Thesis committee}

\section{Promotor}

Prof. Dr H. Komen

Professor of Animal Breeding and Genomics

Wageningen University \& Research

\section{Co-promotors}

Dr P. Bijma

Assistant professor, Animal Breeding and Genomics

Wageningen University \& Research

Dr H. A. Mulder

Associate professor, Animal Breeding and Genomics

Wageningen University \& Research

Prof. Dr L. Rönnegård

Professor of Statistics, Section of Statistics

Dalarna University, Falun, Sweden

Guest professor, Swedish University of Agricultural Sciences, Uppsala, Sweden

\section{Other members (assessment committee)}

Prof. Dr B. J. Zwaan, Wageningen University \& Research

Dr N. Ibánẽz-Escriche, Universitat Politècnica de València, Spain

Prof. Dr J. B. Wolf, University of Bath, United Kingdom

Dr W. Mekkawy, WorldFish, Malaysia

The research presented in this doctoral thesis was conducted under the joint auspices of the Swedish University of Agricultural Sciences and Wageningen Institute of Animal Sciences of Wageningen University \& Research and is part of the Erasmus Mundus Joint Doctorate Program “EGS-ABG”. 


\title{
Genetics of inherited variability Increasing uniformity by reducing competition
}

\author{
Jovana Marjanović \\ WAGENINGEN \\ UNIVERSITY \& RESEARCH \\ SLu \\ ACTA UNIVERSITATIS AGRICULTURAE SUECIAE \\ DOCTORAL THESIS No 2018:16
}

\section{Thesis}

submitted in fulfillment of the requirements for the joint degree of doctor between

Swedish University of Agricultural Sciences

by the authority of the Board of the Faculty of Veterinary Medicine and

Animal Science and

\section{Wageningen University \& Research}

by the authority of the Rector Magnificus, Prof. Dr A.P.J. Mol,

in the presence of the

Thesis Committee appointed by the Academic Board of Wageningen University \& Research and the Board of the Faculty of Veterinary Medicine and Animal Science of the Swedish University of Agricultural Sciences to be defended in public on Friday April 20, 2018

at 4 p.m. in the Aula of Wageningen University 
Marjanović, J.

Genetics of inherited variability: Increasing uniformity by reducing competition. 198 pages.

Joint PhD thesis, Swedish University of Agricultural Sciences, Uppsala, Sweden and Wageningen University, the Netherlands (2018)

With references, with summary in English

ISSN: 1652-6880

ISBN (print version): 978-91-7760-172-2

ISBN (electronic version): 978-91-7760-173-9

ISBN 978-94-6343-753-0

DOI: $10.18174 / 442792$ 


\section{Abstract}

Social interactions are common for all living organisms. In animal breeding, these interactions are of interest as they are often a source of indirect genetic effects (IGEs). An IGE is a heritable effect of an individual on the trait value of another individual. In aquaculture populations and some plants, social interactions have an additional consequence - interactions in the form of competition inflate variability of trait values among individuals. The phenotypic variability of a genotype has been studied as a quantitative trait in itself, and is often referred to as inherited variability. The main objective of this thesis was to study the genetics of inherited variability, with a focus on the relationship between competition (i.e., IGEs) and variability. In the thesis, we used Nile tilapia as a model species. We found that variability of body weight and body size traits in Nile tilapia is heritable, and shows a large genetic coefficient of variation, which offers good opportunities for improvement of uniformity by means of genetic selection.

To study the genetic relationship between social interactions and variability, we developed a quantitative genetic model that integrates both phenomena. In this model, interactions between social partners lead to divergence (competition) or convergence (cooperation) of their phenotypes (e.g., body weight) over their life time. The effects of social interaction in the model are heritable and can evolve. These effects comprise direct genetic effect of the focal individual and IGE of its social partner. With a simulation study we showed that the model yields increased variability of body weight with increase of competition, similar to what is observed in real aquaculture populations. Selection for cooperation will therefore lead to decreased variability. These findings suggest that IGEs may be creating an entire level of genetic variation in variability, that has so far been overlooked. Using existing statistical models, we show that direct genetic effects of competition on variability could be captured with a direct model of inherited variability, and similarly, IGEs of competition could be captured with an indirect model of inherited variability.

According to kin selection theory individuals should show better social behavior, i.e., less competition, towards relatives, which should be reflected in their body weight and the variability thereof. We tested this hypothesis by comparing two treatments in an experiment, in which tilapia were reared in either kin or in non-kin groups. Individuals had significantly higher body weight in kin groups, however, there was no difference in variability of body weight between the two treatments.

Findings of this thesis demonstrate that variability of body weight in tilapia is heritable and that genetic variation in variability may comprise not only direct genetic effects but also IGEs. Studies focusing on evolution of variability/uniformity, therefore, should consider IGEs. 



\section{Table of Contents}

1 - General introduction

9

2 - Genetic parameters for uniformity of harvest weight and body size traits in the GIFT strain of Nile tilapia

3 - Modelling the co-evolution of indirect genetic effects and inherited variability

4 - Capturing indirect genetic effects on phenotypic variability: Competition meets canalization

5 - Effects of relatedness between group mates on body weight and variability of body weight in domestic Nile tilapia

6 - General discussion

Summary

About the author

Publication list

Training and supervision plan

Acknowledgments 



\section{List of publications}

This thesis is based on the work contained in the following papers:

I. Marjanovic J, Mulder HA, Khaw HL, Bijma P (2016). Genetic parameters for uniformity of harvest weight and body size traits in the GIFT strain of Nile tilapia. Genet Sel Evol 48: 41.

II. Marjanovic J, Mulder HA, Rönnegård L, Bijma P (in press). Modelling the coevolution of indirect genetic effects and inherited variability. Heredity. doi: 10.1038/s41437-018-0068-z

III. Marjanovic J, Mulder HA, Rönnegård L, Koning DJ, Bijma P. Capturing indirect genetic effects on phenotypic variability: Competition meets canalization. To be submitted.

IV. Marjanovic J, Mulder HA, Khaw HL, Bijma P. Effects of relatedness between group mates on body weight and variability of body weight in domestic Nile tilapia. To be submitted. 

1

General introduction 



\subsection{Social interactions}

Many traits that are important for agriculture are complex quantitative traits. In animal breeding, it is desirable to improve these traits by means of genetic selection. A complete understanding of the potential of a trait to respond to selection requires identifying all sources of genetic variation underlying the trait. Traditional selection methods only consider the direct genetic effects (DGEs) of an individual's own genes on the phenotypic value of the individual. The environmental effects on a trait expression are generally assumed as non-heritable, and therefore not able to evolve by selection. In certain cases, however, the environment itself may have a genetic basis. This alters the genetic architecture and inheritance of a trait.

Animals are social beings who spend the majority of their lifetime engaged in interactions with conspecifics (Allee, 1927). These social interactions are often the most important part of the environment that individuals experience (Wolf, 2003; Frank, 2007). The environment created by social partners through actions such as competition or cooperation, is referred to as the social environment. Variation in the quality of the social environment can be attributed to traits expressed by social partners. Since these traits may reflect genetic variation, the socially provided environment can be heritable (Wolf et al., 1998; Bleakley and Brodie IV, 2009). The most extensively studied example of heritable environmental effects is the environment provided by a mother to her offspring (Dickerson, 1947; Willham, 1963; Falconer, 1965; Kirkpatrick and Lande, 1989; Cheverud, 2003; Bijma, 2011).

When the environment contains a genetic component, the phenotype of an individual may not only be influenced by its own genes (DGEs), but also by genes of its social partners. This heritable effect of a social partner on trait values of the focal individual is known as an indirect genetic effect (IGE; referred to as associative effects in Griffing, 1967). IGEs give rise to additional genetic (co)variation, which has consequences for trait values and fitness of individuals that interact, and subsequently for the direction and magnitude of response to selection (e.g. Hamilton, 1964; Moore et al., 1997; Wolf et al., 1998).

IGEs have been studied in animals (e.g. Ellen et al., 2014), plants (e.g. Mutic and Wolf, 2007; Brotherstone et al., 2011), and microorganisms (Crespi, 2001), and both in natural (e.g. Wilson et al., 2011) and in domestic populations (e.g. Muir, 1996; Khaw et al., 2016). A number of studies have shown that social interactions can contribute substantially to heritable variation underlying a trait (reviewed by Ellen et al., 2014). 
For animal breeders, social interactions with negative effect on trait values, health, and welfare, are especially of interest. Such interactions have been well-documented for laying hens, where cannibalistic behavior causes mortality (Muir, 1996; Ellen et al., 2008), and for pigs, where competition and tail biting leads to poorer growth and reduced animal welfare (Arango et al., 2005; Camerlink et al., 2013, 2014; Bergsma et al., 2013). In fish species, social interactions such as aggression and competition have been studied for their detrimental effect on growth of the population (medaka, Ruzzante and Doyle, 1991; Atlantic cod, Monsen et al., 2008; Nile tilapia, Khaw et al., 2016).

In summary, both empirical and theoretical work show that IGEs can considerably contribute to the potential of traits to respond to selection, and therefore need to be included in the genetic analysis of traits affected by social interactions.

\subsection{Social interactions and inherited variability}

So far, social interactions have been studied mainly in relation to their effects on fitness and trait values of individuals. However, in aquaculture populations, it has been observed that competition for feed and formation of social hierarchy also increases the variation of trait values among individuals (Jobling, 1995; Cutts et al., 1998; Hart and Salvanes, 2000). The variability of trait values of a genotype, measured either on the same individual multiple times, or on multiple individuals belonging to the same family, can be studied as a quantitative trait on its own. This phenomenon is often referred to as inherited variability, genetic variation in uniformity, or heritable variation in environmental variance (SanCristobal-Gaudy et al., 1998; Mulder et al., 2008; Hill and Mulder, 2010). Genetic variation in trait variability suggests that some individuals are less sensitive to small fluctuations in the environment, which allows them to maintain a stable phenotype.

The study of inherited variability has been an integral part of quantitative genetics for more than 70 years (Waddington, 1942), with growing interest in the topic over the last two decades, largely due to the development of methods to estimate genetic variance in variability (SanCristobal-Gaudy et al., 1998; Sorensen and Waagepetersen, 2003; Mulder et al., 2009; Rönnegård et al., 2010) and increasing empirical evidence for a genetic basis of variability in livestock, aquaculture, and laboratory populations (reviewed by Hill and Mulder, 2010). In addition, variability is an important economic trait in animal production, which further stimulated the research in this area. 
In aquaculture, uniformity of body weight has recently been identified as one of the most important traits to be improved by selective breeding (Sae-Lim et al., 2012; Janssen et al., 2017; Omasaki et al., 2017). Studies in Atlantic salmon, rainbow trout, and Nile tilapia found a large genetic component in variability of body weight (Janhunen et al., 2012; Sonesson et al., 2013; Khaw et al., 2015; Sae-Lim, et al., 2015a; Sae-Lim, et al., 2015b; Marjanovic et al., 2016).

The relationship between competition and phenotypic variability is not unique for aquaculture, but can also be observed in plants. Plant breeders have successfully improved productivity of crops by selecting, partly unintentionally, less competitive phenotypes, which has resulted in more uniform crops (Donald, 1968; Austin et al., 1980; Denison et al., 2003).

These observations suggest that phenotypic variability may also be socially affected trait, with IGEs harboring genetic variation in variability that has so far been overlooked.

\subsection{Models of IGE and inherited variability}

The quantitative genetics of socially-affected traits have been studied in two modelling frameworks: variance component models and trait-based models (McGlothlin and Brodie, 2009; Bijma, 2014).

In variance component models, the phenotype of the focal individual $i\left(P_{i}\right)$ who interacts with a single social partner $j$, is the sum of a direct genetic $\left(A_{D, i}\right)$ and a direct environmental $\left(E_{D, i}\right)$ component originating from the focal individual, and an indirect genetic $\left(A_{I, j}\right)$ and an indirect environmental $\left(E_{I, j}\right)$ component originating from its social partner $j$ (Griffing, 1967):

$P_{i}=A_{D, i}+E_{D, i}+A_{I, j}+E_{I, j}$

In this approach, DGEs and IGEs are estimated as random effects using linear mixed models and information on genetic relationships between individuals (Muir, 2005; Bijma, Muir, Ellen, et al., 2007). When all individuals are both donor and recipient of social interactions, each individual has a direct genetic effect $A_{D, i}$, i.e., a direct breeding value expressed in its own phenotype, and an indirect breeding value $A_{I, i}$, expressed in the phenotype of its social partner. The sum of $A_{D, i}$ and $A_{I, i}$, i.e., the total breeding value, represents the total heritable impact of an individual on the population mean trait value, and the genetic unit of interest in the selection of 
individuals for socially affected traits (Moore et al., 1997; Bijma, Muir, and Van Arendonk, 2007).

The second type of IGE models, i.e., the trait-based models, define IGEs on the phenotype of the focal individual as a function of trait values of its social partners (Moore et al., 1997; Wolf et al., 1998; Bijma, 2014). For example, the level of aggression displayed by focal individual is often affected by body weight of its social partner (Thornhill, 1984; Smith and Brown, 1986). Therefore, for empirical use of this model, the traits causing the indirect effects need to be identified. If we consider interaction of two individuals, where the target trait and the trait causing the IGE are the same, the trait-based model equals (Moore et al., 1997)

$P_{i}=A_{i}+E_{i}+\psi P_{j}$

where $P_{i}$ is the phenotypic value of the focal individual $i, A_{i}$ is the additive genetic effect and $E_{i}$ the environmental effect originating from the focal individual, while $P_{j}$ is the phenotypic value of its social partner $j$. The $\psi$ is known as the "interaction coefficient", and it defines the strength of the social interaction. The $\psi$ can take positive or negative value, and is assumed constant in the population.

Both types of IGE models, however, cannot fully make the connection between competition and variability observed in aquaculture and plant populations, since they model phenotypic variance as largely independent of the level of IGEs (for further explanation see General discussion - Chapter 6). In addition, observations from aquaculture suggest that behavior of a fish towards its social partners depends on its size relative to that of its partners. Therefore, to account for the competitive effect of body weight on growth rate in aquaculture, evolution of body weight needs to be modelled over the life of the interacting individuals. Current IGE models, however, are only applied to the final phenotype.

Quantitative genetics of inherited variability is most commonly studied using a class of models which allow for genetic effects on both the phenotypic mean and the environmental or residual variance of a trait. In the classical quantitative genetic model variation in a phenotype is defined as $\sigma_{P}^{2}=\sigma_{A}^{2}+\sigma_{E}^{2}$ (Falconer and Mackay, 1996), where $\sigma_{A}^{2}$ is the additive genetic variance affecting the mean trait value and $\sigma_{E}^{2}$ is the environmental variance, assumed to be constant for different genotypes. However, when phenotypic variability differs among genotypes, part of that difference may be attributed to genetic variation in environmental variance, i.e. $\sigma_{E}^{2}=A_{v}+E_{v}$, where $A_{v}$ is the breeding value for environmental variance and $E_{v}$ is 
the residual in environmental variance. Models for inherited variability, however, consider variability as a property of the focal individual, affected only by direct genetic effects, while the potential contribution of the social partner is ignored.

In terms of available quantitative genetic models, social interactions and variability are poorly connected. Therefore, there is a need for new models to understand the relationship between competition and variability observed in aquaculture and plants populations, and the potential of inherited variability to respond to selection.

\subsection{Aim and outline of the thesis}

The observed relationship between social interactions and variability on the phenotypic level (Jobling, 1995; Cutts et al., 1998; Hart and Salvanes, 2000; Denison et al., 2003) strongly suggests an underlying genetic relationship between the two phenomena, of which very little is known. The main objective of this thesis, therefore, was to study the genetics of inherited variability and possibilities for its genetic improvement, focusing primarily on the relationship between competition and variability.

Research presented in this thesis is a result of collaboration between Wageningen University \& Research and Swedish University of Agricultural Sciences, in cooperation with WorldFish. WorldFish provided the data for Chapter 2 and the experimental facilities used to generate data for Chapter 5. Previous collaboration between Wageningen University \& Research and WorldFish resulted in a PhD project which aimed to estimate direct and indirect genetic effects on growth rate in Nile tilapia (Khaw, 2015). This thesis builds on that knowledge, but primarily focuses on relationship between social interactions and variability. The large size differences related to competition for feed, together with the desire to reduce these differences by means of genetic selection (Ponzoni et al., 2005, 2011; Khaw et al., 2016), makes Nile tilapia an ideal species to study the relationship between social interactions and variability. Therefore, Nile tilapia was also used as a model species in this thesis.

In Chapter $\mathbf{2}$ we investigate the potential for genetic improvement of inherited variability of harvest weight and body size traits in a domestic Nile tilapia population. We analyzed within-family variance of harvest weight, body length, depth, and width, by applying a double hierarchical generalized linear models (DHGLM) to individual trait values (Rönnegård et al., 2010). In addition to quantifying genetic variation in inherited variability of those traits, we also looked into possibilities of 
The general discussion, Chapter 6, addresses several topics. First, I elaborate on integrating the two fields in quantitative genetics, social interactions and inherited variability. Second, I discuss benefits and downsides of selection for uniformity in domestic and natural populations. Finally, I give perspectives for selection for uniformity, future studies, and possible applications of the model developed in Chapter 3.

\section{References}

Allee WC (1927). Animal aggregations. Q Rev Biol 3: 367-398.

Arango J, Misztal I, Tsuruta S, Culbertson M, Herring W (2005). Estimation of variance components including competitive effects of Large White. J Anim Sci 83:12416.

Austin RB, Bingham J, Blackwell RD, Evans LT, Ford MA, Morgan CL, et al. (1980). Genetic improvements in winter wheat yields since 1900 and associated physiological changes. J Agric Sci 94: 675.

Bergsma R, Mathur PK, Kanis E, Verstegen MWA, Knol EF, Van Arendonk JAM (2013). Genetic correlations between lactation performance and growing-finishing traits in pigs. J Anim Sci 91: 3601-3611.

Bijma $P$ (2011). A general definition of the heritable variation that determines the potential of a population to respond to selection. Genetics 189: 1347-1359.

Bijma P (2014). The quantitative genetics of indirect genetic effects: a selective review of modelling issues. Heredity (Edinb) 112: 61-9.

Bijma P, Muir WM, Van Arendonk J a M (2007). Multilevel selection 1: Quantitative genetics of inheritance and response to selection. Genetics 175: 277-288.

Bijma P, Muir WM, Ellen ED, Wolf JB, Van Arendonk JAM (2007). Multilevel selection 2: Estimating the genetic parameters determining inheritance and response to selection. Genetics 175: 289-99.

Bijma P, Wade MJ (2008). The joint effects of kin, multilevel selection and indirect genetic effects on response to genetic selection. J Evol Biol 21: 1175-88.

Bleakley BH, Brodie IV ED (2009). Indirect genetic effects influence antipredator behavior in guppies: Estimates of the coefficient of interaction psi and the inheritance of reciprocity. Evolution (N Y) 63: 1796-1806.

Brotherstone S, White I, Sykes R, Thompson R, Connolly T, Lee S, et al. (2011). Competition effects in a young sitka spruce (Picea sitchensis, Bong. Carr) clonal trial. Silvae Genet 60: 149-155

Brown GE, Brown JA (1996). Does kin-biased territorial behavior increase kin-biased foraging in juvenile salmonids? Behav Ecol 7: 24-29.

Camerlink I, Turner SP, Bijma P, Bolhuis JE (2013). Indirect Genetic Effects and Housing :Conditions in Relation to Aggressive Behaviour in Pigs. PLoS One 8: 
e65136.

Camerlink I, Ursinus WW, Bijma P, Kemp B, Bolhuis JE (2014). Indirect Genetic Effects for Growth Rate in Domestic Pigs Alter Aggressive and Manipulative Biting Behaviour. Behav Genet 45: 117-126.

Cheverud JM (2003). Evolution in a genetically heritable social environment. Proc Natl Acad Sci 100: 4357-4359.

Crespi B (2001). The evolution of social behavior in microorganisms. Trends Ecol Evol 16: 178-183.

Cutts CJ, Betcalfe NB, Caylor AC (1998). Aggression and growth depression in juvenile Atlantic salmon: the consequences of individual variation in standard metabolic rate. J Fish Biol 52: 1026-1037.

Denison RF, Kiers ET, West SA (2003). Darwinian agriculture: when can humans find solutions beyond the reach of natural selection? Q Rev Biol 78: 145-68.

Dickerson GE (1947). Composition of hog carcasses as influenced by heritable differences in rate and economy of gain. Res Bul la Agric Exp Sta 354: 489-524.

Donald CM (1968). The breeding of crop ideotypes. Euphytica 17: 385-403.

Ellen ED, Rodenburg TB, Albers GAA, Bolhuis JE, Camerlink I, Duijvesteijn N, et al. (2014). The prospects of selection for social genetic effects to improve welfare and productivity in livestock. Front Genet 5: 377.

Ellen ED, Visscher J, van Arendonk JAM, Bijma P (2008). Survival of laying hens: genetic parameters for direct and associative effects in three purebred layer lines. Poult Sci 87: 233-9.

Falconer DS (1965). Maternal effects and selection response. In: Genetics Today, Proc. XIth Int. Congr. of Genet., The Hague, The Netherlands, pp 763-774.

Falconer DS, Mackay TFC (1996). Introduction to quantitative genetics.

Frank SA (2007). All of life is social. Curr Biol 17: R648-R650.

Gerlach G, Hodgins-Davis A, MacDonald B, Hannah RC (2007). Benefits of kin association: related and familiar zebrafish larvae (Danio rerio) show improved growth. Behav Ecol Sociobiol 61: 1765-1770.

Griffing B (1967). Selection in reference to biological groups. I. Individual and group selection applied to populations of unordered groups. Aust J Biol Sci 20: 12739.

Hamilton WD (1964). The genetical evolution of social behaviour. I. J Theor Biol 7: 116.

Hart PJB, Salvanes AG V. (2000). Individual variation in competitive performance of juvenile cod and its consequences for growth. J Mar Biol Assoc UK 80: 569570.

Hepper PG (1986). Kin recognition: functions and mechanisms: a review. Biol Rev 61: 63-93.

Hill WG, Mulder HA (2010). Genetic analysis of environmental variation. Genet Res 
(Camb) 92: 381-395.

Hiscock MJ, Brown JA (2000). Kin discrimination in juvenile brook trout (Salvelinus fontinalis) and the effect of odour concentration on kin preferences. Can J Zool 78: 278-282.

Janhunen M, Kause A, Vehviläinen H, Järvisalo O (2012). Genetics of microenvironmental sensitivity of body weight in rainbow trout (Oncorhynchus mykiss) selected for improved growth. PLoS One 7: e38766.

Janssen K, Berentsen P, Besson M, Komen H (2017). Derivation of economic values for production traits in aquaculture species. Genet Sel Evol 49.

Jobling M (1995). Simple indices for the assessment of the influences of social environment on growth performance, exemplified by studies on Arctic charr. Aquac Int 3: 60-65.

Kareem AM, Barnard CJ (1982). The importance of kinship and familiarity in social interactions between mice. Anim Behav 30: 594-601.

Khaw HL (2015). Social interactions and variability in live body weight in the GIFT strain (Nile tilapia, Oreochromis niloticus) in Malaysia. Doctoral thesis, Wageningen University.

Khaw HL, Ponzoni RW, Yee HY, Aziz MA bin, Bijma P (2016). Genetic and non-genetic indirect effects for harvest weight in the GIFT strain of Nile tilapia (Oreochromis niloticus). Aquaculture 450: 154-161.

Khaw H, Ponzoni R, Yee H, Aziz M, Mulder HA, Marjanovic J, et al. (2015). Genetic variance for uniformity of harvest weight in Nile tilapia (Oreochromis niloticus). Aquaculture 451: 113-120.

Kirkpatrick M, Lande R (1989). The evolution of maternal characters. Evolution ( $N$ Y) 43: 485-503.

Marjanovic J, Mulder HA, Khaw HL, Bijma P (2016). Genetic parameters for uniformity of harvest weight and body size traits in the GIFT strain of Nile tilapia. Genet Sel Evol 48: 41.

McGlothlin JW, Brodie ED (2009). How to measure indirect genetic effects: The congruence of trait-based and variance-partitioning approaches. Evolution ( $N$ Y) 63: 1785-1795.

Monsen BB, Arnesen KR, Toften H, Nielsen HM, Bijma P, Olesen I (2010). Genetics of social interactions in Atlantic cod (Gadus morhua). Proceedings WCGALP.

Moore AJ, Brodie ED, Wolf JB (1997). Interacting Phenotypes and the Evolutionary Process: I. Direct and Indirect Genetic Effects of Social Interactions. Evolution (N Y) 51: 1352-1362.

Muir WM (1996). Group selection for adaptation to multiple-hen cages: selection program and direct responses. Poult Sci 75: 447-458.

Muir WM (2005). Incorporation of competitive effects in forest tree or animal breeding programs. Genetics 170: 1247-59. 
Mulder HA, Bijma P, Hill WG (2008). Selection for uniformity in livestock by exploiting genetic heterogeneity of residual variance. Genet Sel Evol 40: 37-59.

Mulder HA, Hill WG, Vereijken A, Veerkamp RF (2009). Estimation of genetic variation in residual variance in female and male broiler chickens. Animal 3: 1673-1680.

Mutic JJ, Wolf JB (2007). Indirect genetic effects from ecological interactions in Arabidopsis thaliana. Mol Ecol 16: 2371-81.

Omasaki SK, Janssen K, Besson M, Komen H (2017). Economic values of growth rate, feed intake, feed conversion ratio, mortality and uniformity for Nile tilapia. Aquaculture 481: 124-132.

Ponzoni RW, Hamzah A, Tan S, Kamaruzzaman N (2005). Genetic parameters and response to selection for live weight in the GIFT strain of Nile Tilapia (Oreochromis niloticus). Aquaculture 247: 203-210.

Ponzoni RW, Nguyen NH, Khaw HL, Hamzah a, Abu Bakar KR, Yee HY (2011). Genetic improvement of Nile tilapia (Oreochromis niloticus) with special reference to the work conducted by the WorldFish Center with the GIFT strain. Rev Aquac 3: 27-41.

Rönnegård L, Felleki M, Fikse F, Mulder HA, Strandberg E (2010). Genetic heterogeneity of residual variance - estimation of variance components using double hierarchical generalized linear models. Genet Sel Evol 42: 8.

Ruzzante DE, Doyle RW (1991). Rapid behavioral changes in medaka (Oryzias latipes) caused by selection for competitive and noncompetitive growth. Evolution 45 :1936-1946.

Sae-Lim P, Gjerde B, Nielsen HM, Mulder H, Kause A (2015). A review of genotypeby-environment interaction and micro-environmental sensitivity in aquaculture species. Rev Aquac 4: 369-393.

Sae-Lim P, Kause A, Janhunen M, Vehviläinen H, Koskinen H, Gjerde B, et al. (2015). Genetic (co)variance of rainbow trout (Oncorhynchus mykiss) body weight and its uniformity across production environments. Genet Sel Evol 47: 46.

Sae-Lim P, Komen H, Kause A, van Arendonk JAM, Barfoot AJ, Martin KE, et al. (2012). Defining desired genetic gains for rainbow trout breeding objective using analytic hierarchy process. J Anim Sci 90: 1766-76.

SanCristobal-Gaudy M, Elsen J-M, Bodin L, Chevalet C (1998). Prediction of the response to a selection for canalisation of a continuous trait in animal breeding. Genet Sel Evol 30: 423-451.

Smith JM, Brown RLW (1986). Competition and body size. Theor Popul Biol 30: 166179.

Sonesson AK, Odegård J, Rönnegård L (2013). Genetic heterogeneity of within-family variance of body weight in Atlantic salmon (Salmo salar). Genet Sel Evol 45: 41.

Sorensen D, Waagepetersen R (2003). Normal linear models with genetically 
structured residual variance heterogeneity: a case study. Genet Res 82: 207222.

Thornhill R (1984). Fighting and Assessment in Harpobittacus Scorpionflies. Evolution 38:204-214

Wahaj SA, Horn RC Van, Horn TL Van, Dreyer R, Hilgris R, Schwarz J, et al. (2004). Kin Discrimination in the Spotted Hyena (Crocuta crocuta): Nepotism among Siblings. Behav Ecol Sociobiol 56: 237-247.

Wilkinson GS (1984). Reciprocal food sharing in the vampire bat. Nature 308: 181184.

Willham RL (1963). The Covariance between Relatives for Characters Composed of Components Contributed by Related Individuals. Biometrics 19: 18.

Wilson AJ, Morrissey MB, Adams MJ, Walling CA, Guinness FE, Pemberton JM, et al. (2011). Indirect genetic effects and evolutionary constraint: an analysis of social dominance in red deer, Cervus elaphus. J Evol Biol 4: 772-83.

Wolf JB (2003). Genetic architecture and evolutionary constraint when the environment contains genes. Proc Natl Acad Sci 100: 4655-4660.

Wolf JB, Brodie III ED, Cheverud JM, Moore AJ, Wade MJ (1998). Evolutionary consequences of indirect genetic effects. Trends Ecol Evol 13: 64-69. 


\section{6}

General discussion 



\subsection{Introduction}

Social interactions are common in nature and are an important part of the environment experienced by individuals. When individuals interact, their phenotypes may be affected by genes in their social partners. This heritable effect of a social partner on the trait value of the focal individual is known as an indirect genetic effect (IGE) (Griffing, 1967; Moore et al., 1997). IGEs can also be interpreted as a genetic component in the social environment, i.e., the environment created by social partners. In the terms of classical quantitative genetic model, where the trait value of an individual is a function of genetic and environmental effects, $P=G+E$, the $E$-term is partly heritable when IGEs occur (Wolf et al., 1998; Bleakley and Brodie IV, 2009; Bijma, 2014). However, the classical model assumes that the environmental effects are not heritable. Therefore, there was a need to extend the model to incorporate IGEs, which led to development of two modelling frameworks for IGE, variance component models and trait based models.

IGEs may not only affect the mean trait value, but also variation of the trait around its mean. In fish and some plant populations, competition has been shown to increase variability of trait values. In the past two decades, variability has been studied as a genetic trait in its own right. This trait is often referred to as inherited variability or heritable variation in environmental (residual) variance (SanCristobalGaudy et al., 1998; Mulder et al., 2007; Hill and Mulder, 2010). As social interactions are often a source of IGEs, the observed relationship between competition and variability on the phenotypic level (Jobling, 1995; Cutts et al., 1998; Hart and Salvanes, 2000; Denison et al., 2003) strongly suggested an underlying genetic relationship between the two phenomena. Here our knowledge, however, is quite limited, because despite the clear phenotypic relationship between competition and variability, inherited variability has not been connected to competition in quantitative genetic model. On the one hand, variance component and trait-based IGE models cannot fully explain the observed relationship between competition and variability. On the other hand, models for inherited variability treat variability as a property of a single individual.

In this thesis we studied genetics of inherited variability, with specific focus on the relationship between variability and competition, and the contribution of IGEs to genetic variation in variability. 
In Chapter 3 we proposed a quantitative genetic model that allows for indirect genetic effects to lead to differences in variability of trait values, similar to observations in real aquaculture and plant populations. Integrating IGE and inherited variability, and reasons why it was necessary to develop a new model, will be the first topic that I will address in this chapter.

In this thesis we studied genetics of inherited variability. In Chapter $\mathbf{2}$ we investigated the genetic basis of variability in body weight and size in a domestic Nile tilapia population. Chapter $3 \& \mathbf{4}$ focused on the relationship between variability and competition and how to capture genetic effects of competition on variability. In Chapter 5 we investigated the effect of relatedness on the level of variability. Understanding the genetic basis of variability is important in animal and plant breeding, both from an economic and an animal welfare point of view. Breeding for uniformity is an analogue of the evolution of canalization in natural populations (Waddington, 1942). In evolutionary biology, canalization is studied for its role in phenotypic evolution (Flatt, 2005). Genetic changes in variability, therefore may have an important impact in both domestic and natural populations. Benefits and downsides of such impact will be next topic I will address.

Finally, I will conclude this chapter by giving perspectives for selection for uniformity, discuss the need for future studies, and possible applications of the model developed in Chapter 3.

\subsection{Social interactions and inherited variability: bringing two worlds together}

As mentioned above, traits affected by social interactions can be modelled using two theoretical frameworks, variance component models and trait based models. Both of these frameworks have been developed from maternal effects theory, which describes a special case of indirect genetic effects, where indirect effects of a mother on the phenotypes of offspring have a heritable component (Dickerson, 1947; Willham, 1963; Falconer, 1965; Cheverud, 1984; Kirkpatrick and Lande, 1989).

In the variance component model, the phenotypic value of the focal individual $i\left(P_{i}\right)$, who interacts with a single social partner $j$, is a function of a direct genetic effect of the focal individual $\left(A_{D, i}\right)$, an indirect genetic effect attributed to the social partner $\left(A_{I, j}\right)$, and a residual $(e)$ (Griffing, 1967): 
$P_{i}=A_{D, i}+A_{I, j}+e$

In the trait-based model, the indirect genetic effect of the social partner on the trait value of the focal individual is modelled as a function of the trait value of the social partner. If the trait of interest and the trait causing the IGE are the same, the traitbased model (assuming interaction of two individuals) specifies the phenotypic value of the focal individual $i$ as a function of the direct genetic effect of $i\left(A_{i}\right)$, nonheritable effects of $i\left(e_{i}\right)$, and the phenotype of social partner $j\left(P_{j}\right)$ multiplied by an interaction coefficient, $\psi$ (Moore et al., 1997):

$P_{i}=A_{i}+e_{i}+\psi P_{j}$

In the original trait-based IGE-model, the $\psi$ is a population parameter that describes the magnitude of IGEs, i.e., the strength of the social interaction, and is considered constant within a population.

The clear distinction between these models gives them certain advantages and disadvantages in the study of IGEs, depending on the research question and available data. For example, in the variance component model, the traits causing the IGEs do not need to be specified. Instead, the social effect is added to the model as a random genetic effect, and the indirect genetic variance is estimated based on genetic relationships in the data. The variance component model, therefore, gives estimates of direct and indirect genetic effects, but does not disclose the mechanism underlying the IGEs. Trait-based models, in contrast, require knowledge of the traits causing the IGE, but in return quantify the mechanism underlying the social interaction.

To understand the observations from aquaculture and plant populations, where competition for resources increases variability, in this thesis we wanted to integrate IGEs and inherited variability into a single model. Considering available IGE models and models for inherited variability for such study, we encountered the following issues :

1) current IGE-models and models for inherited variability cannot fully explain the observed relationship between competition and variability

2) the interaction coefficient $\psi$ in the trait-based IGE model has the same value for all interacting individuals, i.e., it shows no flexibility 
3) IGEs are usually applied to a "final" phenotype, whereas the effect of competition accumulates over time.

\subsubsection{Modelling the relationship between competition and variability}

In this section I will elaborate on issue number one, by showing the connection between the level of IGEs and variability, or the lack thereof, for each model.

In the variance component model (Equation 1), when pairs of interacting individuals are unrelated, phenotypic variance can be decomposed into the variance of direct genetic effects $\left(\sigma_{A_{D}}^{2}\right)$, the variance of indirect genetic effects $\left(\sigma_{A_{I}}^{2}\right)$, and the residual variance $\left(\sigma_{e}^{2}\right)$ :

$\sigma_{P}^{2}=\sigma_{A_{D}}^{2}+\sigma_{A_{I}}^{2}+\sigma_{e}^{2}$

From here it becomes clear that phenotypic variance is only affected by the variance of indirect genetic effects in the population, not by their level. This model, therefore, was not adequate for our research question, as observations from real populations show that competition and cooperation, i.e., sign of average level of IGEs, have a very different effect on variability, whereas variance is always positive and only gives insight in the variation of IGEs in the population around the mean. This was also demonstrated in Chapter 4, where indirect models for the trait capture only little of the genetic effects of competition on variability.

In the trait-based model, if we assume that $P_{i}$ and $P_{j}$ are the same trait, and that both individuals are both donor and recipient of social interaction, i.e., Equation 2 also applies to individual $j$, then the phenotypic variance on the population level can be derived as follows (Moore et al., 1997):

$P_{i}=A_{i}+e_{i}+\psi\left(A_{j}+e_{j}+\psi P_{i}\right)$

$\left(1-\psi^{2}\right) P_{i}=A_{i}+e_{i}+\psi\left(A_{j}+e_{j}\right)$

Solving the equation gives

$P_{i}=\frac{A_{i}+E_{i}+\psi\left(A_{j}+E_{j}\right)}{1-\psi^{2}} ; \quad P_{j}=\frac{A_{j}+E_{j}+\psi\left(A_{i}+E_{i}\right)}{1-\psi^{2}}$ 
And phenotypic variance equals

$\sigma_{P}^{2}=\frac{\left(1+\psi^{2}\right)\left(\sigma_{A}^{2}+\sigma_{E}^{2}\right)}{\left(1-\psi^{2}\right)^{2}}$

When $|\psi|=1$, the phenotypic values and the phenotypic variance are undefined (Bijma, 2014). Note that Equation 7 gives the phenotypic variance in a population consisting of many interacting pairs of individuals, not the variance within a pair. Equation 7 shows that the level of $\psi$ affects the phenotypic variance, however, the effect is symmetrical for positive and negative values of $\psi$, due to $\psi^{2}$ term in both the numerator and denominator. Figure 1, Panel A, illustrates how phenotypic variance changes with $\psi$. This differs from observations from real populations, where competition leads to increase of phenotypic variability, while cooperation decreases variability.

Now let us consider the variance within a pair ("group") of two individuals $\left(\sigma_{P_{w g}}^{2}\right)$ in the trait-based model

$\sigma_{P_{w g}}^{2}=\operatorname{var}\left(P-P_{\text {average }}\right)=\frac{1}{4} \operatorname{Var}\left(P_{i}-P_{j}\right)$

Using Equation 6, we can express $P_{i}-P_{j}$ as

$P_{i}-P_{j}=\frac{(1-\psi)\left(A_{i}+E_{i}\right)-(1-\psi)\left(A_{j}+E_{j}\right)}{1-\psi^{2}}=\frac{\left(A_{i}+E_{i}\right)-\left(A_{j}+E_{j}\right)}{1+\psi}$

The variance of $P_{i}-P_{j}$ in the trait-based model then becomes

$\operatorname{Var}\left(P_{i}-P_{j}\right)=\frac{2\left(\sigma_{A}^{2}+\sigma_{E}^{2}\right)}{(1+\psi)^{2}}$

and the within-group variance equals

$\sigma_{P_{w g}}^{2}=\frac{1}{2} \frac{\left(\sigma_{A}^{2}+\sigma_{E}^{2}\right)}{(1+\psi)^{2}}$

The final equation shows that the within-group variance depends on $\psi$ rather than $\psi^{2}$, so that positive and negative values of $\psi$ have different effect on within-group 
variance, i.e., negative values lead to higher $\sigma_{P_{w g}}^{2}$, and positive to lower $\sigma_{P_{w g}}^{2}$. This is shown in Figure 1 , Panel $B$, where an increase in $\psi$ causes a drop in variability.

The $b_{i j}$ in our model (Chapter 3 ) measures the effect of a difference in body weight between the social partner and the focal individual on the growth rate of the focal individual. The absolute value of $b_{i j}$ reflects the strength of the social interaction, however $b$ can have both positive and negative values. Negative $b$ indicates competition, positive $b$ cooperation, and an increase in $b$ an increase of cooperation. An increase in cooperation in our model leads to a decrease in variability on both population and within-group level, as shown in Figure 2 in Chapter 3. Deriving expressions for phenotypic and within-group variance for our model is rather challenging, as the phenotype of the focal individual depends on the phenotypes from the previous time point of both social partner and focal individual. Therefore, in this chapter for our model I present the pattern of change of variability as a function of $b$ numerically, by using data simulated in Chapter $\mathbf{4}$ and fitting model with mean and random group effect to the final phenotype, i.e., phenotype at the last time point, using ASReml 4.1 (Gilmour et al., 2015). This model gives estimates for within-group, between-group, and phenotypic variance, which were estimated for populations where average $b$ is $-0.05,0$, or +0.05 (Figure 6.1, Panel D-F).

Comparing our model with the trait-based model, we can see that the main difference occurs for the phenotypic variance. The change in within-group variance shows a similar pattern for both models. Since phenotypic variance includes both within- and between-group variance, the observed difference must be related to the latter.

Starting with the expression from Equation 6, the between-group variance for traitbased model is derived as follows:

The group average is given by

$\bar{P}=\frac{P_{i}+P_{j}}{2}=\frac{\left(A_{i}+E_{i}+A_{j}+E_{j}\right)(1+\psi)}{2\left(1-\psi^{2}\right)}$

The between-group variance equals the variance of the group average, 
$\sigma_{\bar{P}}^{2}=\sigma_{b g}^{2}=\frac{\frac{1}{2}\left(\sigma_{A}^{2}+\sigma_{E}^{2}\right)(1+\psi)^{2}}{\left(1-\psi^{2}\right)^{2}}=\frac{\frac{1}{2}\left(\sigma_{A}^{2}+\sigma_{E}^{2}\right)}{(1-\psi)^{2}}$

Plotting $\sigma_{b g}^{2}$ for different values of $\psi$ using Equation 13 shows an increase in between-group variance with an increase of $\psi$ (Figure 1, Panel C). In our model (Figure 1, Panel F), however, we can see the decrease in the between-group variance. In conclusion, the relationship between competition and variability on the withingroup level is modelled in a similar way in our model (Chapter $\mathbf{3}$ ) and the trait-based model. The main difference between the models can be seen on the population level, where the trait-based model shows symmetrical level of variability for positive and negative values of $\psi$, while our model shows decrease in variability with positive $b$. My expectation is that competition leads to higher variability on both within-group and population level, which has also been noticed for several species of fish (Mccarthy et al., 1992; Jobling, 1995; Ponzoni et al., 2005, 2011). Therefore our model depicts the co-evolution of competition and variability more realistically compared to ordinary trait-based IGE-models.

Finally, I will show that models for inherited variability fail to connect variability and the level of IGE, using the additive model as an example. The phenotypic value of the focal individual $i$ in the classical model is a function of direct genetic effect of $i$ on the mean $\left(A_{m, i}\right)$ and direct environmental effect of $i$ on the mean $\left(E_{i}\right)$ :

$P_{i}=A_{m, i}+E_{i} \quad$ or $\quad P_{i}=A_{m, i}+\chi \sigma_{E, i}$

where $\chi$ is a standard normal deviate, $\chi^{\sim N}(0,1)$ for the environmental effect. With genetic variation in environmental variance:

$\sigma_{E, i}^{2}=\sigma_{E}^{2}+A_{v, i}$

so that

$P_{i}=A_{m, i}+\chi \sqrt{\sigma_{E}^{2}+A_{v, i}}$

where $\sigma_{E}^{2}$ is the mean environmental variance and $A_{v, i}$ is the direct genetic effect of $i$ for environmental (residual) variance. Models for inherited variability, therefore only consider direct genetic effects of the focal individual on its own variability, ignoring a possible contribution of the social partner. We confirmed this observation 


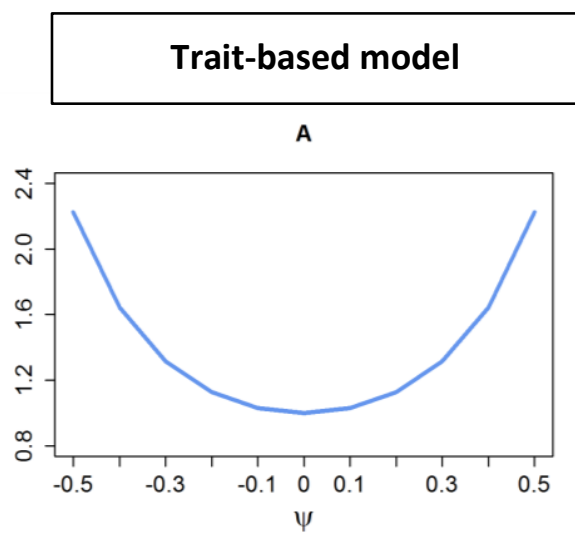

B

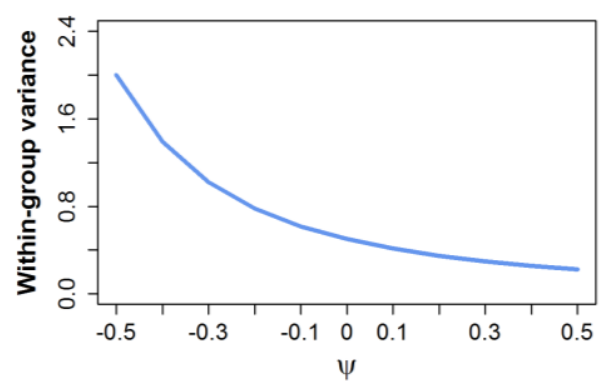

C

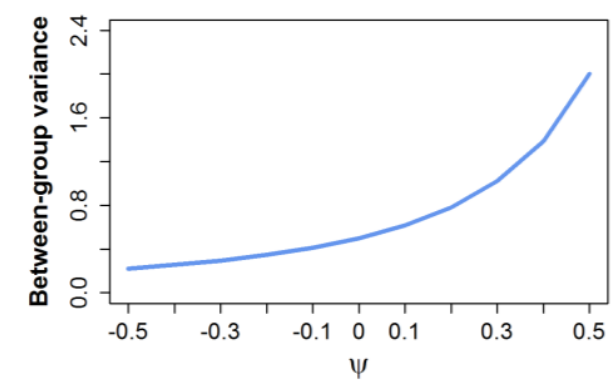

\section{Our model}

D

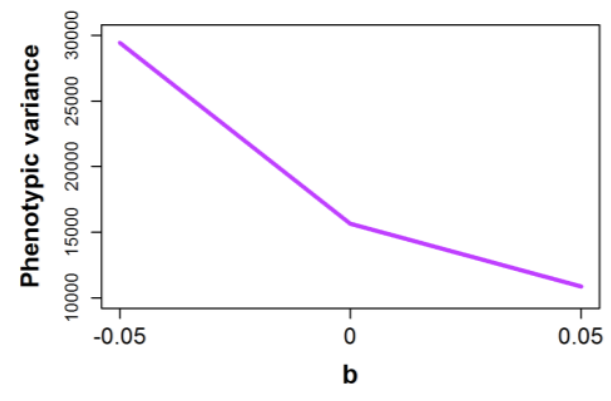

E

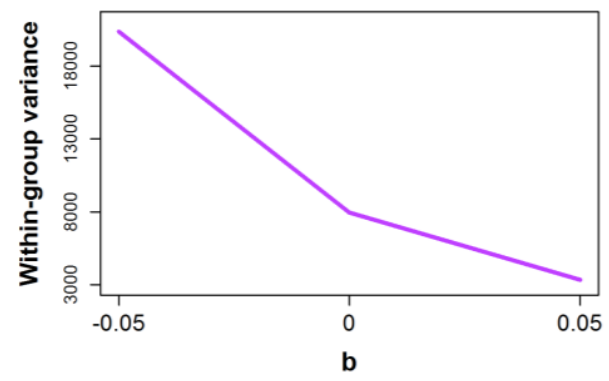

$\mathbf{F}$

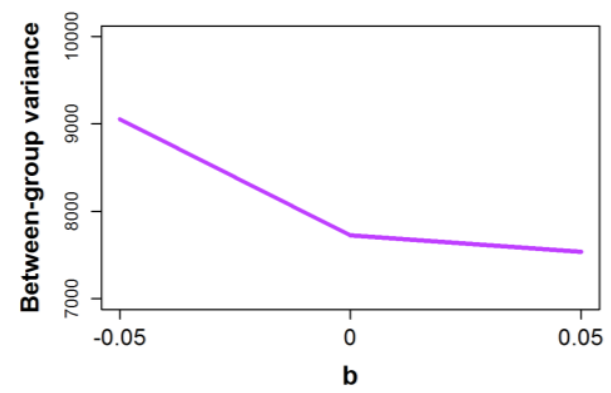

Figure 6.1 Pattern of change in phenotypic, within-group, and between group variance with change in $\psi$ in trait-based model, and change in $b$ in our model. Panels $\mathrm{A}, \mathrm{B}$, and $\mathrm{C}$, were made using Equation 7, 11, and 13, receptively, assuming $\sigma_{A}^{2}+\sigma_{E}^{2}=1$; Panels D, E, and F, were made using estimates from ASReml 4.1, averaged over 10 replicates for each value of $b$. 
in Chapter 4, by applying a direct sire model for inherited variability to simulated data. The model captured almost entirely the direct genetic effects of competition (direct breeding values for $b$ ), but very little of the indirect genetic effect of competition.

\subsubsection{Genetic variation in $\Psi$}

In the ordinary trait-based model, $\psi$ is assumed to be constant, i.e., to have the same value for all interacting individuals. While done for simplicity, the assumption of constant $\psi$ is rather crude and unrealistic. It is more likely that $\psi$ varies within the population, meaning that $\psi$ itself may respond to selection (Chenoweth et al., 2010). Demonstrating genetic variation in $\psi$ is a challenging task, but can be done, for example, by using multiple discrete genotypes, i.e., inbred lines. Relying on such data, Bleakley and Brodie IV (2009) estimated $\psi$ in guppies and showed that it differs between the focal inbred strains. In addition, the level of $\psi$ in some cases also depended on the social (partner) strain, suggesting that both focal and partner strain contribute to variation in $\psi$. Similarly, studies on chemical signaling in $D$. melanogaster (Kent et al., 2008) and sexual display traits in D. serrata (Chenoweth et al., 2010) also found variation in $\psi$.

In our study, we wanted to allow variability and competition to co-evolve. For that purpose, the $b$ itself needed to be heritable. Inspired by the above-mentioned study on guppies, but also by a study on cannibalistic behavior in laying hens, which shows that such behavior depends on genetic effects of both the social partner (the pecker) and the victim (Ellen et al., 2008), we modelled $b$ as a composite quantitative genetic trait. In other words, $b$ expresses genetic variation due to direct genetic effects of the focal individual and indirect genetic effects of the social partner. Related to our trait, it means, that the effect of a difference in body weight between the social partner and the focal individual on the growth of the focal individual, depends on genetic competitiveness of the social partner and genetic resistance to competition of the focal individual. Therefore, $b$ shows genetic variation and can evolve, which facilitates research on evolution of trait variability due to changes in IGEs.

An additional issue with $\psi$ comes from the feedback effect (Moore et al., 1997; Bijma, 2014). The "feedback" refers to the situation where the "indirect" genetic effects of the focal individual affect its own trait value, indirectly through the social partner. For example, the level of aggression in the focal individual affects the level of aggression in the social partner, which subsequently affects the level of aggression in the focal individual. In those cases, $\psi$ is not a true regression coefficient, because 
$P$ and $E$ in Equation 2 are correlated (Bijma, 2014). The $b$ in our model, however, is a true regression coefficient because the phenotype of the focal individual is affected by phenotype of the social partner from the previous time point, but not vice versa. Therefore, time-series data eliminates the problem of feedback.

\subsubsection{Formation of variability}

In many species, fitness of an individual depends on its size relative to the size of the other individuals (Smith and Brown, 1986). Fish that are larger often win fights, which allows them to acquire more resources (Huntingford et al., 2012). Because probability of success in a competitive interaction between individuals depends on body size, individuals tend to modify their behavior based on their body size relative to that of social partner. Larger fish, therefore, are usually aggressive, while smaller ones are submissive (Huntingford et al., 2012). In aquaculture, this causes the formation of a social hierarchy, where large fish are at the top of the hierarchy and have priority to feed, while subordinate fish show lower food intake and growth (Vera Cruz and Brown, 2007). As a consequence, dominant individuals show higher and more stable growth, compared to subordinate fish (Mccarthy et al., 1992). Such high discrepancy in growth ultimately leads to increase of variation in body size in time, which has been observed on both group and population level (Jobling, 1995; Ponzoni et al., 2005, 2011).

This brings us to the third issue related to IGE models - as evident from Equation 1 $\& 2$, these models only consider IGEs on the final phenotype. Observations from aquaculture, however, show that variability develops over time. In our model we simulated growth curves in order to incorporate competitive effect of body weight on the growth of focal individuals and mimic the observations from aquaculture population, therefore giving a more realistic impression of how IGEs affect the level of variability. We did, however, for simplicity assume that direct and indirect genetic effects are the same at the different time points, which from biological perspective may not be true, i.e., the level of competition may differ between different stages of fish life.

\subsubsection{Other traits}

In trait-based models, the indirect effect on the phenotype of the focal individual depends on specific traits of the social partner. Therefore, the traits causing the effect, also known as effector traits, need to be identified. Such information is usually obtained from behavioral studies, and may involve more than one trait. In our model, the effector trait was the difference in body size between the social partner and the 
focal individual, which was chosen based on findings in a number of studies on fish behavior (Huntingford et al., 2012). However, other traits may be used as a predictor of variability of body weight instead, or in addition, to the difference in body size. Most likely, these would be traits related to feeding behavior or feed intake and feed efficiency, i.e., traits that affect growth of individual.

In Chapter 3 \& 4 we demonstrated our model using a fish population as an example. However the model may be applicable to other animals, and to plant populations, where a relationship between competition and variability has been observed. In those populations, effector trait(s) may be very different. For example, in domestic pigs variability of body weight can also be related to social hierarchy (Meese and Ewbank, 1973). Several studies suggested initial weight as a key trait for the rank of a certain individual, while higher body weight later in life may not give a competitive advantage (McBride et al., 1964; Meese and Ewbank, 1973). In plants, traits such as height, branching, leaf area, length and branching of the root, determine the competitive ability of an individual (Denison et al., 2003). The difference in level of these traits between social partner and focal individual may be used as an effector traits to investigate relationship between competition and variability. In addition to differences in trait values in plants, distance between interacting individuals would also be needed to take into consideration, as individuals close to each other may exhibit more competitive interactions compared to those that are spaced more distantly.

\subsection{Benefits and consequences of selection for uniformity}

The main focus of this thesis was on the relationship between competition and variability, which was inspired by observations from aquaculture and plant populations. However, the relationship between these two phenomena may already have existed long before the development of complex organisms and may have played a crucial role in the development of multicellularity.

To understand the evolution of cooperation, scientist often apply game theory, for example a "prisoner's dilemma" game. According to the prisoner's dilemma, when two individuals interact, three outcomes are possible: both individuals cooperate; one individual cooperates while other one cheats; both individuals cheat. The scenario where both individuals cooperate brings the highest payoff for both individuals, but that behavior evolves only under certain conditions. Steven A. Frank (2007) gives several examples to demonstrate how mutual cooperation may have 
been a key component in the development of multicellular organisms. What I find interesting in these examples is how a high level of cooperation also goes with a high level of uniformity. Slime molds, for instance, live most of the time as single cells, but in certain situations, such as food shortage, they may form aggregations. These aggregates consist of two parts - reproductive cells that form spores, and stalk that raises spores up from the ground. It has been noticed that when these aggregations contain genotypes that are represented more in reproductive part rather than in stalks, i.e., cheating genotypes, the reproductive output of the whole aggregate is decreased because of lower stalk (Frank, 2007). Similarly, if genotypes produce cells in such way that they are equally represented in both parts, success of the whole aggregate is increased. Therefore, in slime molds, mutual cooperation leads to higher uniformity, and vice versa, and higher fitness. These cellular organizations can be considered as predecessors of multicellular organisms (Frank, 2007).

To avoid the possibility of cheating genotypes, multicellular organisms develop from a single-cell, so that all tissue cells are essentially clones. Mutations, however may happen, causing genetic variation and conflict within the tissue. If one of the genotypes has a competitive advantage compared to other, for example, faster cell growth, it may result in severe consequences, such as formation of tumors. Uniformity on the tissue level, therefore, is extremely important. Cell mechanisms such as DNA repair system and apoptotic control evolved to eliminate extreme phenotypes, but in addition genetic and environmental canalization may have had an important role in maintenance of uniformity against small changes in genome and environment (Flatt, 2005). Uniformity, therefore may have relevance for evolution of multicellular organisms and for the stable functioning of such organisms.

In natural populations, uniformity may arise through stabilizing selection for an optimal phenotype (Waddington, 1942; Wagner et al., 1997; Flatt, 2005; Edgell et al., 2009). If the phenotype is at, or near optimum, the variation around optimum is disadvantageous, and an increase in uniformity increases mean fitness of the population. In a study on within-family variance of fledging weight in the great tit, authors found evidence of stabilizing selection on within-family variance (Mulder et al., 2016). In addition, their results show that families with a high or low within-family variance had lower fitness compared to families with an intermediate within-family variance. In some species of fish, uniformity in size, shape, and color, may have evolved through increase of survival of those individuals, as phenotypic similarity between fish that swim together make it difficult for a predator to focus on a single prey, which is known as "confusion effect" (Landeau and Terborgh, 1986). In 
conclusion, evolution of uniformity/canalization, is often related to an increase in mean fitness of the population, irrespective of whether such populations consist of single cells or individual organisms.

In domestic populations, uniformity of animal products has a clear economic benefit (Hennessy, 2005). In some cases, an increase in uniformity may also lead to higher survival, for example for litter size in pigs (Sell-Kubiak et al., 2015), and increased welfare, as in aquaculture where uniformity reduces competition and the need for grading (Khaw et al., 2016).

While a reduction of variation may be beneficial, a loss of phenotypic variation may also hinder phenotypic evolution and reduce the ability of a population to adapt to a changing environment (Wagner et al., 1997; Flatt, 2005), which is especially relevant for natural populations. However, while phenotypic variation may be low, the underlying genetic variation may accumulate because it is hidden from the force of natural selection (Wagner et al., 1997; Flatt, 2005). Under extreme environmental conditions, a genotype may become "decanalized", causing more rapid evolution (Flatt, 2005). For example Drosophila heat-shock protein Hsp90 buffers genetic variation, unless a stressful environment occurs, such as change in temperature. Buffering ability then becomes compromised and may lead to the expression of new phenotypes (Rutherford and Lindquist, 1998). These results illustrate that phenotypic canalization can go together with the maintenance of heritable variation, so that canalization does not necessarily threaten adaptive potential.

\subsection{Future perspectives}

Selection for uniformity of body weight in aquaculture could lead to increased profit by producing more fish in the size range that is favored by the consumers, and reducing the need for frequent grading of the fish during the grow-out period, which bares not only financial benefits but also benefits for the welfare of the fish.

Results of theoretical and empirical studies on inherited variability suggest that variability could be reduced by means of genetic selection. However, selection experiments to improve uniformity are scarce, and are mostly limited to laboratory populations (Rendel et al., 1966; Kaufman et al., 1977; Argente et al., 2008; Boldin et al., 2012; Blasco et al., 2017). Findings of Chapter 2, together with estimates of genetic variation in variability in several other species of fish (Janhunen et al., 2012; Sonesson et al., 2013; Sae-Lim, Gjerde, et al., 2015; Sae-Lim, Kause, et al., 2015), 
suggest that aquaculture populations are suitable to validate the estimated genetic parameters by a selection experiment.

Given the finding of Chapter 3, two selection experiments could be performed. A first experiment, where selection is based only on direct genetic effects on variability, and a second experiment where selection involves both direct and indirect genetic effects on variability. These experiments could give us insight into how much of genetic variation in variability could be attributed to variation in IGEs. The experiments should have a group structure with, e.g., two individuals in a group, similar to our simulated data in Chapter 3 \& 4. However, subsequent trials involving larger group sizes may also be conducted to test whether the magnitude of effects of competition change with an increase of group size. Data on both individuals in each group should be collected at several time points. Time-series data would allow to use random regression approach as suggested in Chapter 3, but also the direct model and the indirect model for inherited variability presented in Chapter 4 . Half sib - full sib designs, similar to that proposed in Chapter 4, with multiple observations of within-family variance per sire, and individuals from the same family in both experiments, could be used for estimation of direct and indirect genetic effects of competition. Validation and comparison of the models using real data could make a significant contribution to optimization of methods and models for future studies aiming to estimate genetic effects of competition.

Ideally, these experiments should be performed on aquaculture populations. However, large scale experiments using commercial fish stocks may require considerable investments in finances, facilities, labor, and time. Alternatively, the two proposed selection strategies could be compared by using zebrafish as a model organism. Zebrafish show fast growth and a substantial level of competition, they are small, robust, and easy to maintain. Even though they are not commercial fish, they could elucidate possibilities to improve uniformity in aquaculture, and give an impression of how much IGEs could contribute to the evolution of uniformity. In addition, the genome of the zebrafish has been fully sequenced at high quality, which would facilitate research on genetic and molecular mechanism underlying inherited variability.

One of the main obstacles in incorporating uniformity in aquaculture breeding programs is often high and positive genetic correlation between level and variance of harvest weight, meaning that selection for uniformity will cause decrease in selection response in body weight, which is highly undesirable, especially giving the 
low economic value of uniformity (Janssen et al., 2017). It would be interesting to see how indirect genetic effects for $b$ correlate with genetic effects for body weight, and whether selection on IGEs only, could be used to improve uniformity, without consequences for growth.

In Chapter 3 \& 4 we suggested approaches to estimate genetic effects of competition, more specifically how direct and indirect genetic effects on $b$ could be estimated for each individual. In Chapter $\mathbf{3}$ we indicate that random regression could be used to estimate genetic components of $b$, using group-structured population and time series data, while in Chapter $\mathbf{4}$ we tested models which are only applied to the final phenotype of individuals within group, therefore avoiding need for multiple observations. Such specific type of data may not be easily available, especially for fish growing in commercial setting. However, with the development of new phenotyping techniques that involve video tracking of individuals in 3D space, generating such data could become common practice (see for example idTracker, http://www.idtracker.es/). These techniques would give multiple observations on individual trait values (for example body weight calculated from the 3D image, i.e., volume of the individual) and information on social interactions between individuals.

In Chapter 3 \& 4 we proposed a model for interaction of two individuals, and discussed how our model could be extended to incorporate IGEs of multiple individuals on the growth of the focal individual. With an increase of group size, IGEs of an individual may show a so-called dilution effect, i.e., decrease in magnitude, due to less time spent in interacting with each of its group mates (Bijma, 2010). Dilution of IGEs does not always happen with increase of group size, for example, alarm signaling in birds will have a similar effect in small and large groups. However, with traits such as growth, where the amount of food is limited, dilution is likely to happen. One main assumption of the dilution effect is that social partner interacts with all group members and in equally intensity, hence IGEs get diluted over a large number of individuals. However for large groups, my expectation is that individuals will interact mostly with small number of same/familiar individuals. This would lead to partitioning of a large group into small sub-groups, so that IGEs might not become heavily diluted. I believe identification of such sub-groups could also be possible with new phenotyping techniques, once they scale up to simultaneously track larger numbers of individuals, which is one of the main future goals of the developers of such technologies. 


\subsection{Conclusions}

To overcome issues of current IGE models and models for inherited variability, integrating social interactions and inherited variability required development of a new model, which was presented in this thesis. The model allows for competition and variability to co-evolve, suggesting that uniformity could be increased through improvement of direct and indirect genetic effects. Estimation of genetic effects of competition requires group-structured data, and also observations from multiple time points in case of estimation with random regression. With development of new phenotyping techniques such data may become commonly available, facilitating application of our model. Ideally, contribution of IGEs to evolution of variability should be quantified in a selection experiment.

\section{References}

Argente MJ, García ML, Muelas R, Santacreu MA, Blasco A (2008). Preliminary Results In A Divergent Selection Experiment On Variance For Litter Size In Rabbits. In: Proceedings of the 9th World Rabbit Congress, Verona, Italy, 10-13 June 2008 2008 pp. 121-124,

Bijma P (2010). Multilevel selection 4: modeling the relationship of indirect genetic effects and group size. Genetics 186: 1029-31.

Bijma P (2014). The quantitative genetics of indirect genetic effects: a selective review of modelling issues. Heredity (Edinb) 112: 61-9.

Blasco A, Martínez-Álvaro M, García M-L, Ibáñez-Escriche N, Argente M-J (2017). Selection for environmental variance of litter size in rabbits. Genet Sel Evol 49: 48.

Bleakley BH, Brodie IV ED (2009). Indirect genetic effects influence antipredator behavior in guppies: Estimates of the coefficient of interaction psi and the inheritance of reciprocity. Evolution (N Y) 63: 1796-1806.

Boldin L, Bolet G, Garcia M, Garreau H, Larzul C, David I (2012). Robustesse et canalisation : vision de généticiens. Inra ProdAnim 23 (1): 11-22.

Chenoweth SF, Rundle HD, Blows MW (2010). Experimental evidence for the evolution of indirect genetic effects: changes in the interaction effect coefficient, psi $(\Psi)$, due to sexual selection. Evolution (N Y) 64: 1849-1856.

Cheverud JM (1984). Evolution by Kin Selection: A Quantitative Genetic Model Illustrated by Maternal Performance in Mice. Evolution (N Y) 38: 766.

Denison RF, Kiers ET, West SA (2003). Darwinian agriculture: when can humans find solutions beyond the reach of natural selection? Q Rev Biol 78: 145-68.

Dickerson GE (1947). Composition of hog carcasses as influenced by heritable differences in rate and economy of gain. Res Bul la Agric Exp Sta 354: 489-524.

Edgell TC, Lynch BR, Trussell GC, Palmer AR (2009). Experimental Evidence for the 
Rapid Evolution of Behavioral Canalization in Natural Populations. Am Nat 174: 434-440.

Ellen ED, Visscher J, van Arendonk JAM, Bijma P (2008). Survival of laying hens: genetic parameters for direct and associative effects in three purebred layer lines. Poult Sci 87: 233-9.

Falconer DS (1965). Maternal effects and selection response. In: Genetics Today, Proc. XIth Int. Congr. of Genet., The Hague, The Netherlands,, pp 763-774.

Flatt T (2005). The Evolutionary Genetics of Canalization. Q Rev Biol.

Frank SA (2007). All of life is social. Curr Biol 17: R648-R650.

Gilmour AR, Gogel BJ, Cullis BR, Welham SJ, Thompson R (2015). ASReml User Guide Release 4.1. VSN International Ltd.

Griffing B (1967). Selection in reference to biological groups. I. Individual and group selection applied to populations of unordered groups. Aust J Biol Sci 20: 12739.

Hennessy DA (2005). Slaughterhouse Rules: Animal Uniformity and Regulating for Food Safety in Meat Packing. Am J Agric Econ 87: 600-609.

Hill WG, Mulder HA (2010). Genetic analysis of environmental variation. Genet Res (Camb) 92: 381-395.

Huntingford F, Jobling M, Kadri S (2012). Aquaculture and behavior. Wiley-Blackwell.

Janhunen M, Kause A, Vehviläinen H, Järvisalo O (2012). Genetics of microenvironmental sensitivity of body weight in rainbow trout (Oncorhynchus mykiss) selected for improved growth. PLoS One 7: e38766.

Janssen K, Berentsen P, Besson M, Komen H (2017). Derivation of economic values for production traits in aquaculture species. Genet Sel Evol 49.

Jobling $M$ (1995). Simple indices for the assessment of the influences of social environment on growth performance, exemplified by studies on Arctic charr. Aquac Int 3: 60-65.

Kaufman PK, Enfield FD, Comstock RE (1977). Stabilizing Selection for Pupa Weight in TRIBOLIUM CASTANEUM. Genetics 87: 327-41.

Kent C, Azanchi R, Smith B, Formosa A, Levine JD (2008). Social Context Influences Chemical Communication in D. melanogaster Males. Curr Biol 18: 1384-1389.

Khaw HL, Ponzoni RW, Yee HY, Aziz MA bin, Mulder HA, Marjanovic J, et al. (2016). Genetic variance for uniformity of harvest weight in Nile tilapia (Oreochromis niloticus). Aquaculture 451: 113-120.

Kirkpatrick M, Lande R (1989). The evolution of maternal characters. Evolution ( $N$ Y) 43: 485-503.

Landeau L, Terborgh J (1986). Oddity and the 'confusion effect' in predation. Anim Behav 34: 1372-1380.

McBride G, James JW, Hodgens N (1964). Social behaviour of domestic animals. IV. Growing pigs. Anim Prod 6: 129-139. 
Mccarthy ID, Carter CG, Houlihan DF (1992). The effect of feeding hierarchy on individual variability in daily feeding of rainbow trout, Oncorhynchus mykiss (Walbaum). J Fish Biol 41: 257-263.

Meese GB, Ewbank R (1973). The establishment and nature of the dominance hierarchy in the domesticated pig. Anim Behav.

Moore AJ, Brodie ED, Wolf JB (1997). Interacting phenotypes and the evolutionary process: i. direct and indirect genetic effects of social interactions. Evolution ( $N$ Y) 51: 1352-1362.

Mulder HA, Bijma P, Hill WG (2008). Selection for uniformity in livestock by exploiting genetic heterogeneity of residual variance. Genet Sel Evol 40: 37-59.

Mulder HA, Gienapp P, Visser ME (2016). Genetic variation in variability: Phenotypic variability of fledging weight and its evolution in a songbird population. Evolution (N Y) 70: 2004-2016.

Ponzoni RW, Hamzah A, Tan S, Kamaruzzaman N (2005). Genetic parameters and response to selection for live weight in the GIFT strain of Nile Tilapia (Oreochromis niloticus). Aquaculture 247: 203-210.

Ponzoni RW, Nguyen NH, Khaw HL, Hamzah A, Bakar KRA, Yee HY (2011). Genetic improvement of Nile tilapia (Oreochromis niloticus) with special reference to the work conducted by the WorldFish Center with the GIFT strain. Rev Aquac 3: 27-41.

Rendel JM, Sheldon BL, Finlay DE (1966). Selection for Canalization of the Scute Phenotype. II. Am Nat 100: 13-31.

Rutherford SL, Lindquist S (1998). Hsp90 as a capacitor for morphological evolution. Nature.

Sae-Lim P, Gjerde B, Nielsen HM, Mulder H, Kause A (2015). A review of genotypeby-environment interaction and micro-environmental sensitivity in aquaculture species. Rev Aquac.

Sae-Lim P, Kause A, Janhunen M, Vehviläinen H, Koskinen H, Gjerde B, et al. (2015). Genetic (co)variance of rainbow trout (Oncorhynchus mykiss) body weight and its uniformity across production environments. Genet Sel Evol 47: 46.

SanCristobal-Gaudy M, Elsen J-M, Bodin L, Chevalet C (1998). Prediction of the response to a selection for canalisation of a continuous trait in animal breeding. Genet Sel Evol 30: 423-451.

Sell-Kubiak E, Duijvesteijn N, Lopes MS, Janss LLG, Knol EF, Bijma P, et al. (2015). Genome-wide association study reveals novel loci for litter size and its variability in a Large White pig population. BMC Genomics.

Smith JM, Brown RLW (1986). Competition and body size. Theor Popul Biol.

Sonesson AK, Odegård J, Rönnegård L (2013). Genetic heterogeneity of within-family variance of body weight in Atlantic salmon (Salmo salar). Genet Sel Evol 45: 41.

Vera Cruz EM, Brown CL (2007). The influence of social status on the rate of growth, 
eye color pattern and Insulin-like Growth Factor-I gene expression in Nile tilapia, Oreochromis niloticus. Horm Behav.

Waddington $\mathrm{CH}$ (1942). Canalization of development and the inheritance of aquired characters. Nature 150: 563-565.

Wagner GP, Booth G, Bagheri-Chaichian H (1997). A Population Genetic Theory of Canalization. Evolution (N Y) 51: 329.

Willham RL (1963). The Covariance between Relatives for Characters Composed of Components Contributed by Related Individuals. Biometrics 19: 18.

Wolf JB, Brodie III ED, Cheverud JM, Moore AJ, Wade MJ (1998). Evolutionary consequences of indirect genetic effects. Trends Ecol Evol 13: 64-69. 

Summary 



\section{Summary}

Social interactions are common in nature and are an important part of the environment experienced by individuals. In the traditional quantitative genetic model, the phenotype of an individual is determined by the direct effect of its own genes and an environmental effect. With social interactions, however, the phenotype of an individual may also be affected by genes of its social partners. Such effects are known as Indirect Genetic Effects (IGE). IGEs can contribute substantially to heritable variation underlying the trait, and may even reverse the direction of response to selection. A related topic is the inheritance of phenotypic (or residual) variability. The variability of trait values of a genotype, measured either repeatedly on the same individual, or on multiple individuals belonging to the same family, has been studied as a quantitative trait in its own right. This trait is often referred to as inherited variability, heritable variation in environmental variance, or environmental canalization. Results demonstrated substantial genetic variation in variability for many traits. In some species, IGE and inherited variability are related via competition. In aquaculture species and some plants, for example, competition inflates variation of trait values among individuals.

As social interactions are often a source of IGEs, the observed relationship between social interactions and variability on the phenotypic level, strongly suggests an underlying genetic relationship between the two phenomena, of which very little is known. The main objective of this thesis, therefore, was to study the genetics of inherited variability and possibilities for its genetic improvement, focusing primarily on the relationship between competition and variability, and using Nile tilapia as a model species.

In Chapter 2 we investigate the potential for genetic improvement of inherited variability of harvest weight and body size traits in a domestic Nile tilapia population. We analyzed within-family variance of harvest weight, body length, depth, and width, by applying a double hierarchical generalized linear models to individual trait values. Our results showed substantial genetic variation in variability of all analyzed traits, suggesting good prospects for the genetic improvement of uniformity by means of genetic selection. For example, residual variance of harvest weight could be reduced by $58 \%$ with one generation of selection, while proportional change in phenotypic variance would be $36 \%$. Selection for lower variability of harvest weight in Nile tilapia, however, would come with a consequence on the level of harvest weight, due to high and positive estimated genetic correlation between the two. 
Not only direct, but also indirect genetic effects may contribute to genetic variation in variability, as hinted by observations from real populations. In Chapter 3 we make a first step towards understanding the genetic relationship between social interactions and variability, by presenting a quantitative genetic model that integrates both phenomena. In our model, competition between social partners leads to divergence of their phenotypes (e.g., body weight) over their life time. The effects of competition in our model are heritable, and therefore, can evolve. These effects comprise direct genetic effect of the focal individual and indirect genetic effect of its social partner. Simulation results show that our model yields increased variability of body weight with increase of competition, similar to what is observed in real aquaculture populations. Selection for cooperation, i.e., lower competition, will therefore lead to decreased variability. These findings suggest that we may have been overlooking an entire level of genetic variation in variability, the one due to IGEs.

To exploit genetic variation in inherited variability originating from IGEs, we need statistical models to capture this effect. In Chapter 4 we investigate the potential of current statistical models for inherited variability and trait values, to capture the direct and indirect genetic effects of competition on variability. Our results show that a direct model of inherited variability almost entirely captures the direct genetic effect of competition on variability, as illustrated by high correlations between estimated genetic effects and simulated direct breeding values. Similarly, an indirect model of inherited variability captures indirect genetic effects of competition. Models for trait levels, however, capture only little of the genetic effects of competition. Capturing genetic effects of competition, therefore could be possible with direct and indirect models of inherited variability, but may require a two-step analysis.

According to kin selection theory, genetic relatedness should influence social behavior, because individuals able to interact differently with kin vs. non-kin would have higher inclusive fitness. In addition to fitness benefits in natural populations, reduced competition may also lead to increased performance in agricultural populations. One potential way to reduce competition and increase yield and uniformity of trait values in Nile tilapia is to utilize the consequences of past kin selection, i.e., the evolution of kin discrimination and cooperative behavior among relatives. In this study we compared two experimental treatments: rearing of fish in kin groups vs. rearing in non-kin groups, in order to investigate whether relatedness affects performance traits in domestic Nile tilapia. We analyzed average body 
weight, standard deviation and CV of body weight, and survival, between the two treatments. Results of our study show that individuals had significantly higher body weight in groups composed of kin $(8.6 \pm 2.6 \mathrm{~g})$, indicating that domestic Nile tilapia may exhibit kin-biased behavior. However, there was no difference in variability of body weight and survival between the two treatments.

In Chapter 6, I showed why integrating social interactions and inherited variability required development of a new model, and what are the advantages of the new model, compared to current IGE models and models for inherited variability. The most striking difference between the models comes from modelling of relationship between competition and variability. IGE models and models of inherited variability cannot fully explain this relationship between competition and variability as observed in real population, especially on the population level. Our model, however, allows for indirect genetic effects to lead to differences in variability of trait values, on both group and population level. Furthermore, in this chapter I discussed benefits and consequences of selection for uniformity, and proposed future empirical studies that could give insight into biological relevancy of the theoretical possibility that IGEs contribute to genetic variation in variability. 

About the author 



\section{About the author}

Jovana Marjanović was born on $8^{\text {th }}$ of February 1987 in Bijeljina, Bosnia and Herzegovina. In 2010 she obtained her bachelor degree in Molecular Biology from the University of Novi Sad, Republic of Serbia, with specialization in human physiology. The following year she pursued her master degree in Molecular Biology at the same University, with focus on Molecular Genetics. For her master thesis she studied internal transcribed spacer II (ITSII) and cytochrome oxidase I (COI) as potential barcodes to be used to study phylogenetic relationships among members of the hoverfly genus Merodon (Diptera, Syrphidae), in collaboration with the Finnish Museum of Natural History. After her graduation, in 2013 she was accepted as a PhD candidate in the European Graduate School in Animal Breeding and Genetics program. Her PhD project was a result of a collaboration between Wageningen University \& Research and Swedish University of Life Sciences. Jovana had the opportunity to work in both universities, and in addition, in 2016 she has spent one month at WorldFish, in Penang, Malaysia, as a visiting scientist. During her PhD Jovana studied genetics of inherited variability, particularly the relationship between competition and inherited variability. She developed a quantitative genetic model that integrates both phenomena and described possibilities to capture the genetic effects of competition on variability. The results of her research over the course of her PhD are presented in this thesis. In 2017 Jovana started working as a postdoc at Wageningen Livestock Research on the "ReDiverse" project, that aims to increase resilient and competitive use of European Red dairy breeds. 

Publication list 



\section{Peer reviewed papers}

Marjanovic J, Mulder HA, Khaw HL, Bijma P (2016). Genetic parameters for uniformity of harvest weight and body size traits in the GIFT strain of Nile tilapia. Genet Sel Evol 48: 41.

Marjanovic J, Mulder HA, Rönnegård L, Bijma P (in press). Modelling the co-evolution of indirect genetic effects and inherited variability. Heredity. doi: 10.1038/s41437-018-0068-z.

Khaw HL, Ponzoni RW, Yee HY, Aziz MA bin, Mulder HA, Marjanovic J, et al. (2016). Genetic variance for uniformity of harvest weight in Nile tilapia (Oreochromis niloticus). Aquaculture 451: 113-120.

\section{Manuscripts in preparation}

Marjanovic J, Mulder HA, Rönnegård L, Koning DJ, Bijma P. Capturing indirect genetic effects on phenotypic variability: Competition meets canalization. To be submitted.

Marjanovic J, Mulder HA, Khaw HL, Bijma P. Effects of relatedness between group mates on body weight and variability of body weight in domestic Nile tilapia. To be submitted. 


\section{Conference proceedings}

Marjanovic J, Mulder HA, Khaw HL, Bijma P. Genetic parameters for within-family variance of harvest weight in Nile tilapia (Oreochromis niloticus). $10^{\text {th }}$ WCGALP, Vancouver, Canada, 2014, 273.

Marjanovic J, Mulder HA, Khaw HL, Bijma P. Genetic parameters for uniformity of harvest weight in the GIFT strain of Nile tilapia estimated using double hierarchical generalized linear models. ISGA XII, Santiago de Compostela, Spain, 2015.

Marjanovic J, Mulder HA, Khaw HL, Bijma P. Genetic Heterogeneity of Residual Variance in GIFT Nile tilapia. 66 $6^{\text {th }}$ EAAP, Warsaw, Poland, 2015, 21:217.

Marjanovic J, Mulder HA, Bijma P. Modelling the relationship between social interactions and inherited variability. $5^{\text {th }}$ ICQG, Madison, Wisconsin, 2016.

Marjanovic J, Mulder HA, Rönnegård L, Bijma P. Modelling the co-evolution of indirect genetic effects and inherited variability. Gordon Research Seminar and Gordon Research Conference in Quantitative Genetics \& Genomics, Galveston, Texas, 2017. 


Training and supervision plan 

Training and supervision plan

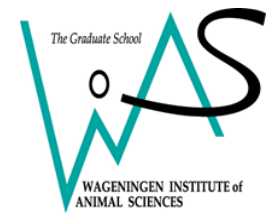

The basic package (7 ECTS)

EGS-ABG Introduction course, Addis Ababa, Ethiopia

2013

EGS-ABG Summer Research School - Sustainable

animal breeding and food security, Addis Ababa,

2013

Ethiopia

Research ethics, Uppsala, Sweden

EGS-ABG Fall Research School - Emerging technologies

in animal breeding, Wageningen, The Netherlands

Scientific exposure (16 ECTS)

International conferences

$10^{\text {th }}$ WCGALP, Vancouver, Canada

2014

ISGA XII, Santiago de Compostela, Spain

2015

$66^{\text {th }}$ EAAP, Warsaw, Poland

2015

$5^{\text {th }}$ ICQG, Madison, USA

2016

Gordon Research Seminar, Galveston, Texas

2017

Gordon Research Conference, Galveston, Texas

2017

\section{Seminars and workshops}

WIAS Science Day, Wageningen, The Netherlands

2014

Workshop Carousel, Wageningen, The Netherlands

2014

WIAS Science Day, Wageningen, The Netherlands

2015

Societal impact, Wageningen, The Netherlands

2015

Aquaculture workshop, Penang, Malaysia

\section{Presentations}

$10^{\text {th }}$ WCGALP, Vancouver, Canada, oral

ISGA XII, Santiago de Compostela, Spain, oral

$66^{\text {th }}$ EAAP, Warsaw, Poland, oral

$5^{\text {th }}$ ICQG, Madison, USA, poster

Gordon Research Seminar, Galveston, Texas, oral

Gordon Research Conference, Galveston, Texas, poster 
In-depth studies (19 ECTS)

Disciplinary and interdisciplinary courses

Introduction to theory and implementation of

genomic selection, Wageningen, the Netherlands

2014

NOVA course - Linear models in animal breeding,

Lofoten, Norway

2015

In depth course genotype by environment interaction,

uniformity and stability, Wageningen, The Netherlands

2015

\section{Advanced statistics courses}

Advanced statistical and genetical analysis of complex data using ASReml 4, Wageningen, The Netherlands

Modern statistics for the life sciences, Wageningen,

the Netherlands

2014

\section{PhD students' discussion groups}

Quantitative genetics discussion group, Wageningen,

The Netherlands

Quantitative genetics study days, Uppsala, Sweden

\section{MSc level courses}

Genetic improvement of livestock, Wageningen, The

Netherlands

Professional Skills Support Courses (3 ECTS)

Techniques for writing and presenting scientific paper

Presenting with Impact

Career assessment

Data management planning

Reviewing a scientific paper

\section{Research Skills Training (2 ECTS)}

Getting started with ASReml

External training period - SLU, Sweden \& WorldFish,

Malaysia 
Didactic Skills Training (5 ECTS)

Supervising practicals

Animal breeding and genetics

2014-2015

Supervising theses

BSc thesis

Management Skills Training (1 ECTS)

Organization of seminars and courses

Aquaculture round table meeting

Education and Training Total

53 ECTS 

Acknowledgments 

Four years have passed. PhD done. I can't believe it! It seems as if just yesterday I walked into WUR campus and started this whole adventure. It was not always easy, but all in all, I had a great time. And I have many of you to thank for that. I will try to do you justice here.

Piter, I learned so much from you in these four years, and not only about science. You also showed me how it looks like to be a good supervisor. Being a great scientist, teacher and a guide is only one part of the equation. You are someone who genuinely cares about his students, and for that you have both my admiration and gratitude. I enjoyed immensely working with you and I feel privileged to had the opportunity to do so. Thank you for introducing me to the wonderful world of social interactions and IGE and for all those talks on "broader" science topics, they were always so interesting. Thank you for the time, patience, and knowledge. For all your support, encouragement, and belief in me, I will probably never be able to thank you enough.

Han, from the moment I started my PhD you and I got along very well, which made working with you really enjoyable and easy. You are someone who truly loves science, and for me that was inspiring. Thank you for teaching me about inherited variability/uniformity/environmental canalization/genetic heterogeneity of environmental (residual variance) etc. :) It is an incredibly interesting topic that offers so much more to explore, and I am happy to had the opportunity to work on that topic with you. Your office door was always open for me, and it didn't bother you that I often took it as a sign to come in and chat about science $(:)$ Thank you!

Lars, we finally met personally in the third year of my PhD. I really enjoyed all our meetings and talks about science, involving not only animal breeding, but evolutionary biology and behavioral genetics, too. Your scientific knowledge is so diverse! Thank you for teaching me more about DHGLM and for showing me how elegant $R$ codes can be $:$ Y You were always so excited about my PhD project and that was very motivating. It was a pleasure to work with you. Tack!

DJ, science comes in many forms and I often feel that you have the ability to see the beauty in all of them. You could find interesting and exciting points in any project, including my own, and you always had good insights and suggestions. Alas, I still didn't come up with a catchy name for my QG model! I really liked our fikas and talks about science news and interesting (read weird) biology facts. Thank you for inviting me to join you for a workshop in WorldFish. I had a great time in SLU, and you made sure that I feel welcomed. Thank you for everything. 
Hooi Ling, it was really nice working with you, and I am glad that we still keep in touch. You were an important part of my PhD I learned a lot from you, especially about aquaculture. You always had kind words for me and you welcomed me so nicely during my visit at WorldFish. For all that and more, thank you.

Johan, you were there for the first half of my PhD. During this time we had several meetings that were very important for me. You cheered for me and you encouraged me to do things, to be more bold. I would leave those meetings feeling more confident. I want to thank you for that, it meant a lot.

Hans, you joined the project in the last year of my PhD as my promotor, but even before that you were aware of my research as we often talked about it and aquaculture in general. I enjoyed our meetings about my research and I appreciate all advices you gave me regarding my future career steps. For my defense, you had to deal with a great amount of paperwork, and somehow you managed, while keeping smile on your face $(;)$ Thank you!

Dear Ada and Lisette, thank you for always being friendly and for help with all the paperwork and everything else that I needed help with. I would be lost without you both. Alex, thank you for being kind and for always finding time to help me with computer related issues.

To all my fellow PhDs from EGS-ABG - I am thankful for the opportunity to meet you all and to be part of our big family. We always had such fun times at our Summer Research Schools in October and Fall Research Schools in February, and we keep organizing meet ups at every conference we go, a tradition I hope will keep on going. We truly made connections for life, and I am happy that it is so. Edine, hvala ti puno što si me kontaktirao na početku mog doktorata, da mi poželiš dobrodšlicu u EGSABG i primpremiš sa korisnim informacijama $(;)$.

To all my colleagues and friends at ABG, big thank you for being such an amazing group of people. I enjoyed the work part and the social part of my PhD.

The beginnings are the hardest, but at the start of my PhD I had the best support group. Sonia, we started our PhDs together and for the large part of it we went through the same experiences and encountered the same issues, and it was really good to have someone by my side who fully understands. Without you, PhD wouldn't be nearly as fun. For all the talks and laughs, for amazing trips, and for always being there for me, merci. (Or was it bonjour? (-)). Tessa and Hamed, my first office mates, 
thank you for all the help with programming at the beginning, and for being such a wonderful source of laughter. I loved our time together, and I really miss our office at Zodiac. Tessa, you were a great friend and immense support from the beginning of my $\mathrm{PhD}$, and it only makes sense that you are also there at the end of it. I am very happy that you are my paranymph. Yogesh, thank you for great talks during our lunches in Zodiac and for always being so friendly. Juanma, thank you for teaching me also some nice words in Spanish (-), for tortillas de patatas, for great trips and lots of laughs, and for being tremendous source of support from the beginning of my PhD to this day. Hadi, thank you for all the talks and for making sure I understand what is really important in life. Sandrine, I wondered if I should cluster you with WUR or SLU, when you are both, just like you are both French and Brazilian :-). I leave you here, because this is where we met. You helped me many, many times and you were there to listen and give good advice every time I needed it. Thank you for being friendly face here and in SLU. I would also like to say thank you to Mandy, Katrijn, Ewa, Floor, Yvonne, Amabel, Gareth, Pascal, Panya, Mahlet, Tom, Kasper, Marcos, Jeremy, Rianne, Sanne, Mirte, Rodrigo, Robert, Kyle, Bert, Maria, Claudia, Shuwen, Samuel, Qiuyu, Harmen, Chiara, Martijn, Anouk, Esther, Aniek, Lucas, Grum, Andre, Gabriel, Gus, Nancy, Wossenie, Ole, Mario, Henk, Liesbeth, Bart, John, and many many others from the ABG team. Mario, thank you for letting me be a part of ReDiverse project.

I have spent my third year at SLU and want to thank everyone from the department for making me feel welcome from the day one. I enjoyed the diverse science at $\mathrm{VH}$ faculty, all the meetings and seminars, our fikas with always amusing talks, BBQs and "playing" Finnish baseball, Taco Tuesdays and "singing" dinner parties (:). You are a wonderful department, with great people and I had best of times there. A year went very fast and I still remember how hard it was to say goodbye to all of you on my last day (cake helped a bit (-)). I hope I'll still have the opportunity to visit you in the future.

To my SLU mafia! You are by far the nicest, most fun, mafia there is! Thank you Suvi, Agnese, Chrissy, Shizhi, Bingjie, Berihu, Sandrine, Kim, Josh, Juan, Ahmed, Merina, Thomas, Thu, Hadrien, Margot, Sofia, for all the fun times, and there were many! I will forever remember our spexes, how could I forget - we sang, danced and even did some Kung Fu fighting to defend Josh's thesis :- I miss you all very much.

Chrissy, I couldn't have wished for a better office mate! You are such a nice, friendly, creative person, and you were an amazing support during my PhD. And that support came in form of words and in form of secret stash of snickers in the office $(;)$. I was 
very happy that you accepted to be my support once more, this time as my paranymph.

During my PhD I visited WorldFish in Penang, and I want to thank Hooi Ling, John Benzie, Claire and Yeong Yeong for receiving me and for organizing my stay. I enjoyed very much learning more about your work and seeing GIFT breeding program. John, you were a wonderful host, and enjoyed our talks and meetings. Hooi Ling, Claire, and Yeong Yeong you were a great tour guides and you have put a lot of effort to show me all the beauties of Penang - thanks for making my stay such a fun experience. Hooi Ling, Hoong Yip, Khairul, thank you for all the help with the experiment, it couldn't have been done without you.

Alexander, you were there for me in good and in bad times. Without your help, support, and advices I don't think I could have made it till the end. I owe you a big thank you.

Ana, Tamara, Sanja, Jelena, Igore, Cecika, Draganče, hvala vam za sve ove godine divnog druženja, što ste mu uvijek bili podrška, i što me niste zaboravili iako sam daleko. Neka prijateljstva su jednostavno neraskidiva.

Tetkić, za sve razgovore, savjete, brojne email-ove tokom svih ovih godina, i što si uvijek bila ponosna na mene, hvala.

Bato, ovaj doktorat bi bio mnogo teži da nije bilo tvoje podrške i ohrabrivanja. Hvala što si uvijek vjerovao u mene. Daco, Kaća i Tea, hvala vam što ste bile najljepša distrakcija od doktorata. Sa vama u zivotu, sve ima više smisla.

Mama i tata, vama hvala najviše. Za sve što ste mi pružili, za neizmjernu ljubav, za silne razgovore i poruke pune podrške, za svu vašu brigu. Volim vas. Nadam se da ste ponosni. 


Colophon 


\section{Colophon}

The research described in this thesis was supported by the European Commission (within the framework of the Erasmus-Mundus joint doctorate "EGS-ABG") and Wageningen University \& Research. WorldFish provided data used in Chapter 2, and experimental facilities and material used to generate data for Chapter 5.

The cover of the thesis was designed by Piotr Sell.

The thesis was printed by ProefschriftMaken | Digiforce. 